\title{
Sunflower storage proteins are transported in dense vesicles that contain proteins homologous to the pumpkin vacuolar sorting receptor PV 72
}

\author{
María Isabel Molina \\ Department of Plant Biology \\ Michigan State University \\ East Lansing, MI 48824-1312 USA \\ Tel: 5173539399 \\ Fax: 5173531926 \\ E-mail: molinam3@msu.edu \\ Marisa Otegui \\ Department of Botany \\ University of Wisconsin \\ 224 Birge Hall- 430, Lincoln Drive \\ WI 53706-. USA \\ Tel: 6082655703 \\ Fax: 6082637509 \\ E-mail: otegui@wisc.edu \\ Silvana Petruccelli* \\ Centro de Investigación y Desarrollo en Criotecnología de Alimentos \\ Facultad de Ciencias Exactas \\ Universidad Nacional de La Plata \\ Calle 47 y 116 (1900) \\ La Plata, Argentina \\ Tel/Fax: 54221 4249287/4254853 \\ E-mail: silvana@biol.unlp.edu.ar
}

Financial support: ANPCyT (Agencia de Promoción Científica y Tecnológica)-ASAGIR (PICTO-13156). SP is member of the research career of CONICET (Argentina).

Keywords: developing sunflower seeds, storage proteins, transport pathway, vacuolar sorting, vacuolar sorting receptor.

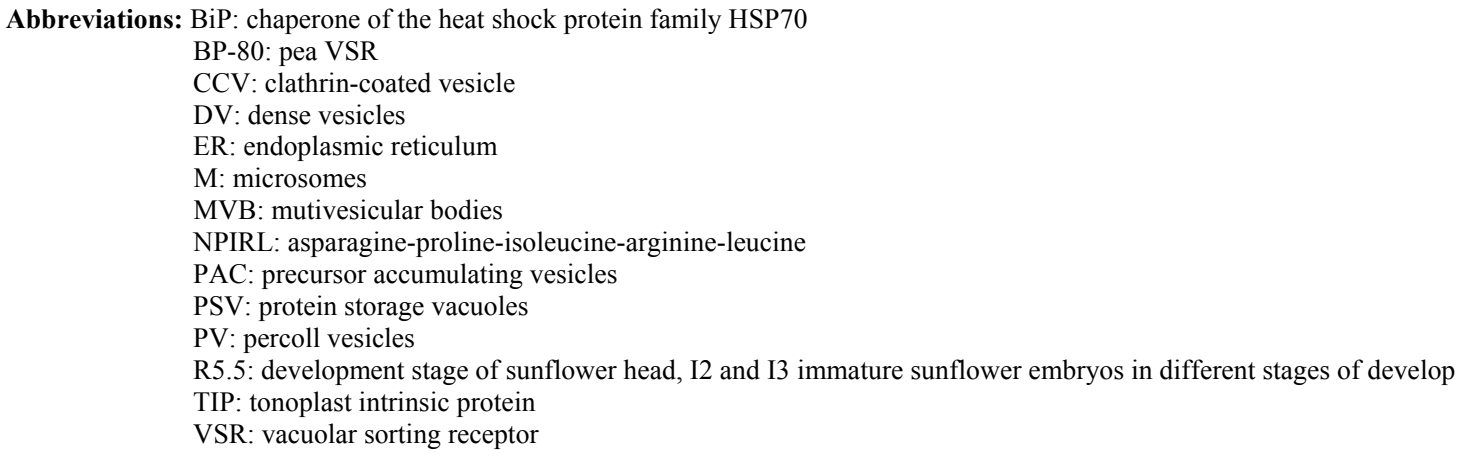

Storage proteins are transported to a special storage compartments in seeds by Golgi dependent or independent pathways depending on the plant species. The aim of this work was to study the sunflower storage protein transport pathway and identified component of the sorting machinery. Immature sunflower seeds were analyzed by subcellular fractionation (using percoll and sucrose gradients) and electron microscopy. The vesicles isolated with percoll, have precursors of $11 \mathrm{~S}$ globulins, $\alpha$-TIP, $\delta$-TIP, BiP, and two proteins that have homology to the pumpkin vacuolar sorting receptor PV72. Sucrose isolated vesicles have the same composition than percoll ones, except for the lack of BiP and the presence of only one protein that has reactivity with pea VSR BP80. Electronic micrographies of developing seeds show that the formation of electron dense aggregates starts in the endoplasmic reticulum, and that these aggregates are very abundant in the trans-Golgi apparatus, where release of dense vesicles happens. These vesicles contain a homolog of PV72 in

* Corresponding author 
their membranes. Storage proteins are also detected in multivesicular bodies whose membranes have reactivity with PV72 serum. All these results indicated that sunflower storage proteins are transported to protein storage vacuoles by a Golgi dependent pathway in a process in which homologous of PV72 are involved.

Seed storage proteins accumulate in a special compartment that has not equivalent in yeast and mammalians and that is called Protein Storage Vacuoles (PSV). Study of the transport pathway to this compartment is very important not only for the role of storage proteins in human and animal nutrition and also for the possibility of accumulate, in this compartment, recombinant proteins which applications in diagnostic or therapeutic. The transport pathway to PSV has been well characterized only in pea and pumpkin (Hara-Nishimura et al. 1998; Hinz et al. 1999). Storage proteins in peas are transported in electron dense vesicles (DV) that start to bud off in the cis-Golgi apparatus and that lack the vacuolar sorting receptor (VSR) BP-80 that is found only in clathrin coated vesicles (CCV) (Hinz et al. 1999; Hillmer et al. 2001). In pea, this receptor has been involved only in the transport to lytic vacuoles (LV) (Hillmer et al. 2001). In contrast, in pumpkin storage protein accumulates in large vesicles termed precursor accumulating vesicles (PAC) whose origin in the endoplasmic reticulum (ER) and that have an homologous of the pea VSR BP-80, called PV72 (Hara-Nishimura et al.
1998). This family of VSR has been related to several processes and it is not clear if they are really involved in storage proteins transport. In Arabidopsis seeds in which this VSR (termed AtELP1) has been knock-out, a partial secretion of storage proteins is observed but some proteins accumulate in PSV, nevertheless the introduction of this gene re-establish the normal phenotype (Shimada et al. 2003). In addition, this receptor interacts with NPIRL motif that is typical of proteins sorted to lytic vacuoles (Ahmed et al. 2000), is a marker of multivesicular bodies (Tse et al. 2004) and have a role in mobilization of storage proteins (Laval et al. 2003).

The aim of this work was to study the storage proteins transport pathway in developing sunflower seeds and analyze the role of homologous of the VSR BP- 80 in the sorting process.

\section{MATERIALS AND METHODS}

\section{Material}

Developing sunflower Helianthus annuus L, TC 3003.

\section{Subcelullar fraccionation}

Transport vesicles carrying storage proteins were separated from microsomes (M) and lytic vesicles (CCV) using two different subcellular fractionation procedures: percoll

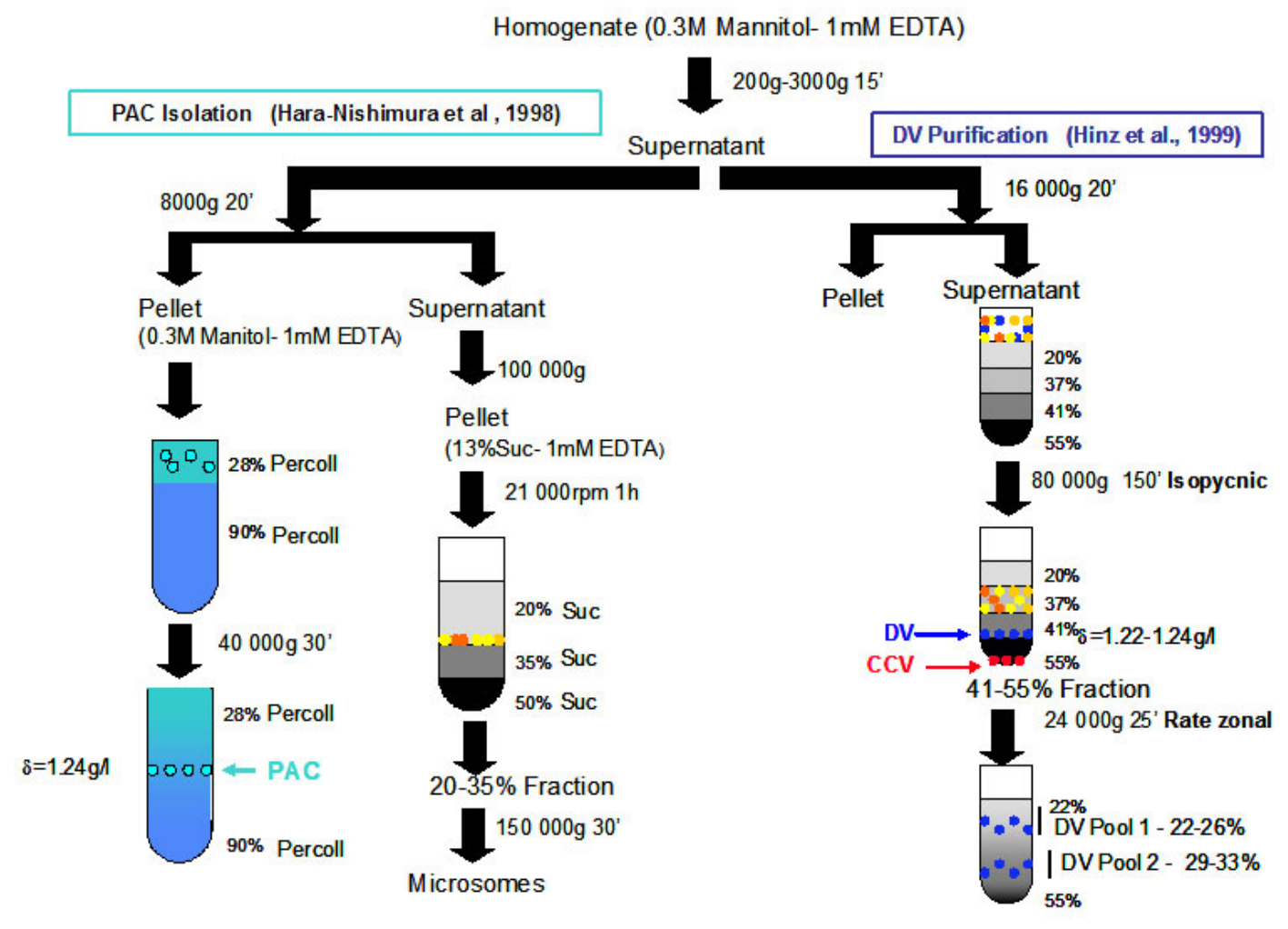

Figure 1. Subcellular fractionation of immature sunflower seeds. 
gradients essentially as described Hara-Nishimura et al. (1998) and sucrose gradients (Hinz et al. 1999); as it is presented in Figure 1.

The fractions were analyzed by Western Blot with sera against sunflower $11 \mathrm{~S}$ globulins, $\alpha$-TIP (PSV marker), $\delta$ TIP (vegetative vacuoles marker), BiP (ER marker), AtELP1 (Arabidopsis VSR), PV72 (pumpkin VSR) and BP-80 (pea VSR) both to identify components of the transport machinery and to check the purity of the different fractions.

Protein Storage Vacuoles (PSV) were isolated from mature sunflower seeds with glycerol (Hara-Nishimura et al. 1998).

\section{Electronic microscopy}

Developing cotyledons were loaded in sample holders filled with a solution of $0.1 \mathrm{M}$ Suc, frozen in a Baltec HPM 010 high-pressure freezer (Technotrade, $\mathrm{NH}$ ), and then transferred to liquid nitrogen for storage. Substitution was performed in $0.2 \%(\mathrm{w} / \mathrm{v})$ uranyl acetate plus $0.2 \%(\mathrm{v} / \mathrm{v})$ glutaraldehyde in acetone at $-90^{\circ} \mathrm{C}$ for $120 \mathrm{hrs}$ and warmed to $-50^{\circ} \mathrm{C}$ for $24 \mathrm{hrs}$. After several rinses with acetone, samples were infiltrated with Lowicryl HM20 (Electron Microscopy Sciences, PA) during $48 \mathrm{hrs}$ and polymerized at $-50^{\circ} \mathrm{C}$ under UV light for $72 \mathrm{hrs}$. Ultrathin sections were mounted placed on formvar coated nickel grids and immunolabeling was performed with the sera described above followed by incubation with a $15 \mathrm{~nm}$ gold-labeled secondary antibody.

\section{RESULTS AND DISCUSSION}

Sunflower seeds storage mainly $11 \mathrm{~S}$ globulins, whose precursor subunits or proglobulins suffer a proteolytic cleavage being transformed into acidic and basic polypeptides as appear in mature PSV. Seeds in different stages of develop were analyzed by Western blot to establish the reproductive stage with maximum amount of $11 \mathrm{~S}$ proglobulins. To this end flowers at bud stage R5:5 (R5.5 means that 50 percent of the head has bloomed or is blooming) were chosen and the embryos separated and classified according to their size in immature 1 (I1; < 5 $\mathrm{mg})$, I2 (5 - $15 \mathrm{mg}), \mathrm{I} 3(15-30 \mathrm{mg})$ and I4 (> $30 \mathrm{mg})$. The maximum amount of precursors of storage proteins were detected in I 2 and 13 embryos, therefore these sizes were chosen to isolate transport vesicles using percoll (Percoll vesicles, PV) and sucrose (SV) gradients (Figure 1). The different fractions obtained using these methods were analyzed by Western blot. Both PV and SV fractions have $11 \mathrm{~S}$ proglobulins and the tonoplast intrinsic proteins: $\alpha$-TIP y $\delta$-TIP that are usually found in storage vacuoles (Figure 2a and Figure 2b). PV has also BiP (Figure 2a), similar to pumpkin PAC (Hara-Nishimura et al. 1998) that can be the result of BiP association with partially folded or unfolded proteins; although ER contamination can not be excluded. In contrast, SV fraction lacks BiP (Figure 2b). Processing of proteins ( $\alpha$-TIP) start to be detected at embryos at stage I3 (Figure 2a). Both PV and SV have two bands that are recognized by the pumpkin VSR PV72, sera while only one of them is recognized by AtELP serum (Figure 2c). The pea VSR serum has a weak reactivity with PV, but strongly recognized sucrose fractions SV1 and SV2 (Figure 2c); the last result is different from that obtained for pea DV (Hinz et al. 1999). Percoll vesicles do not have reactivity with the last serum therefore from the biochemical point of view are different from sucrose fraction (Figure 2c). These results suggest the presence of VSRs in sunflower storage proteins transport vesicles that have homology with both pumpkin PV72 and At-ELP. In contrast pea transport vesicles lack these receptors.

Storage protein transport pathway was also analyzed by electronic microscopy. In immature cotyledons, formation a

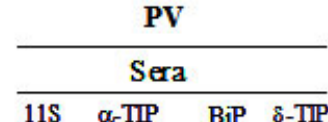

Stage

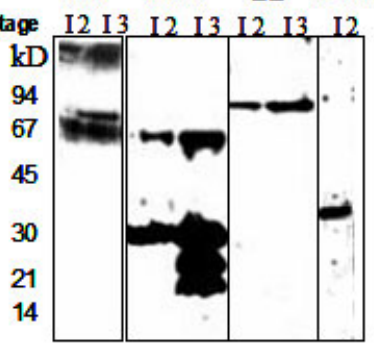

$\mathbf{b}$

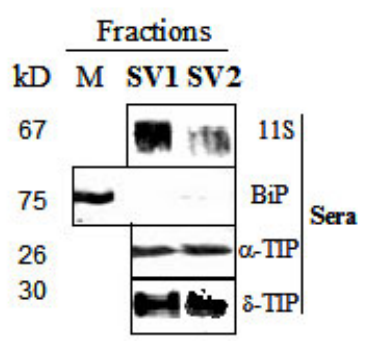

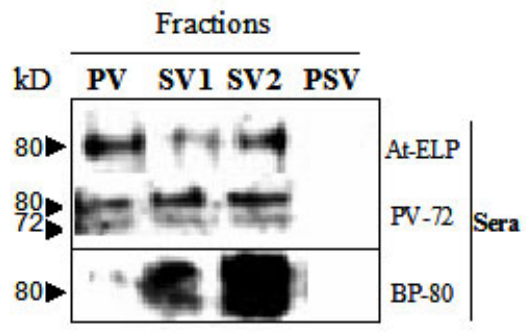

Figure 2. Biochemical characterization of sunflower transport percoll vesicles (PV, part a) and sucrose vesicles (SV, part b) fractionated from immature seeds at stages $\mathbf{I 2}$ and 13 . Presence of proglobulins was analyzed under non reducing conditions with a serum specific to sunflower $11 \mathrm{~S}$ globulins (11S). Association with the chaperon BiP was analyzed with BiP specific antibody. Sera specific to tonoplast intrinsic proteins $\alpha$ and $\delta$ ( $\alpha$-TIP and $\delta$-TIP) were used to characterized the nature of transport vesicles (vacuolar markers). Association of proglobulins with the chaperon BiP was evaluated with BiP specific sera. The presence of vacuolar sorting receptors in PV and SV was studied with sera specific to Arabidposis, pumpkin and pea vacuolar sorting receptors (At-ELP, PV 72 and BP-80 sera, respectively, Part c) Endosplasmic reticulum (microsomes, M) and protein storage vacuoles (PSV) isolated from mature seeds were used as controls. Molecular weight markers $(\mathrm{kD})$ are shown on the left. 
of electron dense aggregates starts to be observed in the ER (Figure 3a, arrows). This phenomenon has not been observed in other developing seeds such as soybean and can be related to the highest hydrophobicity and lower water solubility of sunflower 11S globulins (Molina et al. 2004). In developing soybean cotyledons, in which expression of $7 \mathrm{~S}$ globulins, that are highly soluble, is suppressed; unusual aggregation of $11 \mathrm{~S}$ globulin is observed also in the ER (Mori et al. 2004). Presence of large vesicles coated by ribosome as pumpkin PAC vesicles was not observed (Hara-Nishimura et al. 1998). Aggregation of storage proteins becomes more intense in the Golgi apparatus; especially in the trans-Golgi where a large number of aggregates come out (Figure $3 b$ ) and are released forming DV. In contrast in pea, formation of dense vesicles start at the cis-Golgi (Hillmer et al. 2001). Two kinds of vesicles containing storage proteins are observed: dense vesicles that have electron dense area surrounded by a membrane and multivesicular bodies that have a clear region between the electron dense core and the membrane (Figure 3c and Figure 3d). The last one can be the results of fusion of DV to lytic compartments that have the proteases involved in storage protein processing. The membranes of DV and MVB had reactivity with anti-PV72 (Figure 3d), what support the role of this receptor in the sorting process of storage proteins. The biochemical data shown above was confirmed by the immunogold electron micrographies that shown that the electron dense regions has storage proteins (Figure 3c) and that membrane of both DV and MVB have reactivity to anti-PV72 serum (Figure 3d). Taking into account the size of MVB, the presence of VSRs, particularly BP-80 that in pea has been observed only in lytic compartment, and partially processed proteins, the fraction isolated with sucrose gradients could be MVB.
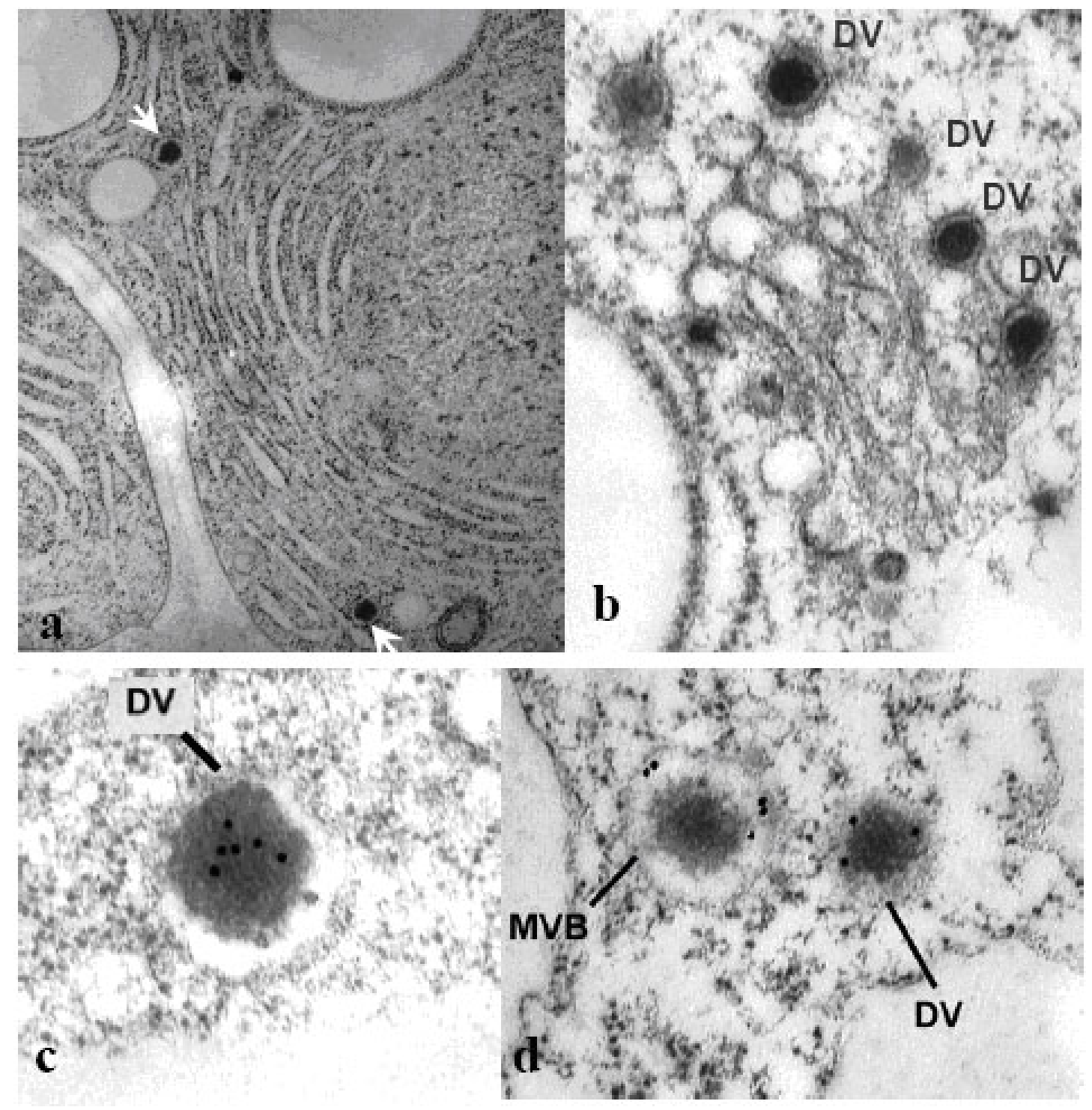

Figure 3. Ultrastructure of immature sunflower cotyledons and immunolocalization of storage proteins and vacuolar sorting receptors in the transport vesicles. Formation of electron-dense aggregates containing storage proteins began to be observed in the ER (part a, arrows). Further aggregation is observed in the trans-Golgi where dense vesicles (DV) bud off (part b). Immunogold labeling with serum specific to sunflower $11 \mathrm{~S}$ globulin shows that electron-dense aggregates are composed by storage proteins (part c). Membranes in both DV and mutivesicular bodies are recognized by PV72-pumpkin- specific serum (part d). 
In conclusion, sunflower storage proteins are transported in dense vesicles that bud off from the Golgi apparatus and contain homologous of pumpkin PV 72.

\section{REFERENCES}

AHMED, S.U.; ROJO, E.; KOVALEVA, V.; VENKATARAMAN, S.; DOMBROWSKI, J.E.; MATSUOKA, K. and RAIKHEL, N.V. The plant vacuolar sorting receptor AtELP is involved in transport of $\mathrm{NH}(2)-$ terminal propeptide-containing vacuolar proteins in Arabidopsis thaliana. Journal of Cell Biology, 2000, vol. 149, no. 7, p. 1335-1344.

HARA-NISHIMURA, I.; SHIMADA, T.; HATANO, K.; TAKEUCHI, Y. and NISHIMURA, M. Transport of storage proteins to protein storage vacuoles is mediated by large precursor-accumulating vesicles. Plant Cell, 1998, vol. 10 , no. 5 , p. $825-836$.

HILLMER, S.; MOVAFEGHI, A.; ROBINSON, D.G. and HINZ, G. Vacuolar storage proteins are sorted in the ciscisternae of the pea cotyledon Golgi apparatus. Journal of Cell Biology, 2001, vol. 152, no. 1, p. 41-50.

HINZ, G.; HILLMER, S.; BÄUMER, M. and HOHL, I. Vacuolar storage proteins and the putative vacuolar sorting receptor BP-80 exit the Golgi apparatus of developing pea cotyledons in different transport vesicles. The Plant Cell, 1999, vol. 11, no. 8, p. 1509-1524.

LAVAL, V.; MASCLAUX, F.; SERIN, A.; CARRIERE, M.; ROLDAN, C.; DEVIC, M.; PONT-LEZICA, R.F. and GALAUD, J.-P. Seed germination is blocked in Arabidopsis putative vacuolar sorting receptor (atbp80) antisense transformants. Journal of Experimental Botany, 2003, vol. 54, no. 381 , p. 213-221.

MOLINA, M.I.; PETRUCCELLI, S. and AÑÓN, M.C. Effect of $\mathrm{pH}$ and ionic strength modifications on thermal denaturation of the 11S globulin of sunflower (Helianthus annuus). Journal of Agricultural and Food Chemistry, 2004, vol. 5, no. 20, p. 6023-6029.

MORI, T.; MARUYAMA, N.; NISHIZAWA, K.; HIGASA, T.; YAGASAKI, K.; ISHIMOTO, M. and UTSUMI, S. The composition of newly synthesized proteins in the endoplasmic reticulum determines the transport pathways of soybean seed storage proteins. The Plant Journal, 2004, vol. 40, no. 2, p. 238-249.

SHIMADA, T.; FUJI, K.; TAMURA, K.; KONDO, M., NISHIMURA, M. and HARA-NISHIMURA, I. Vacuolar sorting receptor for seed storage proteins in Arabidopsis thaliana. Proceedings of the National Academy of Science of the United States of America, 2003, vol. 100, no. 24, p. 16095-16100.
TSE, Y.C.; MO, B.; HILLMER, S.; ZHAO, M.; WAN LO, Z.; ROBINSON, D. and JIANG, L. Identification of multivesicular bodies as prevacuolar compartments in Nicotiana tabacum BY-2 Cells. Plant Cell, 2004, vol. 16, no. 3, p. 672-693. 